\title{
Review Article \\ Pharmaceutical Properties and Applications of a Natural Polymer from Grewia mollis
}

\author{
Elijah I. Nep, Patricia O. Odumosu, Ndidi C. Ngwuluka, \\ Patrick O. Olorunfemi, and Nelson A. Ochekpe \\ Biomaterials and Drug Delivery Research Group, Faculty of Pharmaceutical Sciences, University of Jos, PMB 2084, Jos 930001, Nigeria \\ Correspondence should be addressed to Elijah I. Nep; elijah.nep@biodrudel.com
}

Received 22 March 2013; Accepted 16 June 2013

Academic Editor: Alain Durand

Copyright (c) 2013 Elijah I. Nep et al. This is an open access article distributed under the Creative Commons Attribution License, which permits unrestricted use, distribution, and reproduction in any medium, provided the original work is properly cited.

\begin{abstract}
The use of naturally occurring biocompatible materials has been the focus of recent research activity in the design of dosage forms for immediate and controlled release formulations. Grewia gum is an intracellular gum obtained by extraction from the inner stem bark of the shrub Grewia mollis (Malvaceae). It grows abundantly (wild or cultivated) in the middle belt region of Nigeria, and the mucilage has been used by indigenes of this belt as thickener in soups. Grewia gum has been investigated for potential applications in pharmaceutical dosage forms. The industrial extrapolation of the applications of the gum has, however, been slowed by the limited structural, toxicological, and stability data available on the gum. This paper highlights ethnobotanical uses of $G$. mollis shrub and discusses the structural features, functional properties, and applications of grewia gum with emphases on its pharmaceutical potentials.
\end{abstract}

\section{Introduction}

Plant materials are playing increasing role as alternatives to chemical food additives and synthetic pharmaceutical excipients. Natural polysaccharide gums swell to form highly viscous solutions or dispersions in aqueous media. They have the advantage of biocompatibility, low cost, and relative abundance [1] compared to their synthetic counterparts. They are widely used in the pharmaceutical industry as polymers in various drug delivery systems [2-7].

Grewia polysaccharide gum is a natural resource that could be used as an excipient in the pharmaceutical industry in Nigeria to reduce the costs of pharmaceutical products. It may provide a suitable alternative to the synthetic counterparts which are expensive and mostly imported. It is obtained by extraction (maceration in cold or hot water) of the inner stem bark of the edible plant G. mollis, Juss (Malvaceae). In Nigeria, G. mollis from which the gum is extracted grows abundantly (wild or cultivated) in the middle belt region of the country where it is used as thickener in local delicacies.

This review delineates the ethnobotanical uses, physicochemical properties, structural properties, and the potential applications of the gum in drug delivery systems.

\section{Grewia mollis Plant}

G. mollis belongs to the flowering plant genus, Grewia. It was formerly placed in the family Tiliaceae or Sparrmanniaceae. Today most authors place the genus in the mallow family Malvaceae.

2.1. Botany. The plant has been described $[8,9]$ as a shrub or small tree growing to attain a height of $10.5 \mathrm{~m}$ with young branches densely stellate-pubescent. The young branches turn dark grey to black or reddish brown when older.

The leaves of the plant are elliptic to elliptic-oblong, usually between 2.0 and $14.5 \mathrm{~cm}$ long and 0.7 and $5.5 \mathrm{~cm}$ wide. They are acute to slightly acuminate at the apex, broadly rounded or obliquely truncate at the base. The leaf margins are coarsely and sharply serrate, more or less glabrous to sparsely minutely stellate-pubescent above, but densely and finely greyish to brownish white-pubescent beneath [9].

The flowers are yellow and bisexual; sepals 6-10 $\mathrm{mm}$ long; petals obviate to oblong, 4-6 mm long, $\pm 2 \mathrm{~mm}$ wide, and sometimes notched at the apex. The ovary is $1.5-2 \mathrm{~mm}$ long and densely hairy [9]. 
TABLE 1: Ethnomedicinal uses of G. mollis plant.

\begin{tabular}{|c|c|c|c|}
\hline Use & Plant part & Preparation & References \\
\hline Wound healing & Bark, leaves & Mucilages are applied to ulcers, cuts, sores, and snake bites & {$[9,13]$} \\
\hline Cough & Bark, roots & Decoction & {$[9,13]$} \\
\hline Fever & Bark Leaves, and fruit & Extract of bark and/or leaves. Fruits are also eaten for this purpose & {$[9,13]$} \\
\hline Diarrhoea & Stem bark & Decoction & {$[9,24]$} \\
\hline Child birth Pain & Stem bark, leaves & Maceration, decoction & {$[9,13]$} \\
\hline Colic & Bark, leaves & Infusion & [9] \\
\hline Constipation & Bark & Mucilage & {$[9]$} \\
\hline Rickets & Leaves & Decoction & {$[9]$} \\
\hline Palpitation & Roots, leaves & Decoction & {$[9]$} \\
\hline Sore eyes & Root shavings & Sap squeezed out and applied under the eyelid & {$[9]$} \\
\hline Rheumatism & Roots & Paste & {$[9,13]$} \\
\hline Anal prolapse & Bark & Pounded and dissolved in water & {$[9,24]$} \\
\hline
\end{tabular}

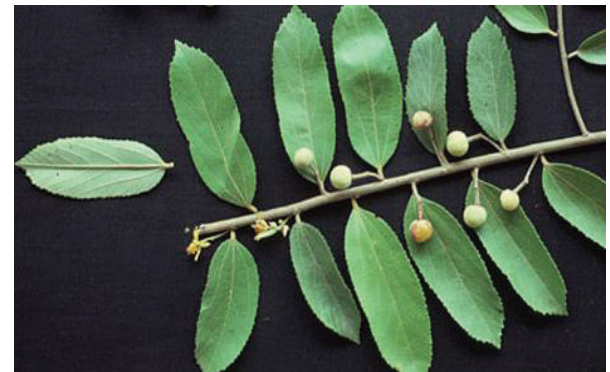

Figure 1: G. mollis plant. The figure is adapted from http://www .prota4u.org/ [10].

The fruit has been described as unlobed and globose drupe of about $4-7 \mathrm{~mm}$ long and $5-7 \mathrm{~mm}$ wide, covered with a fine whitish tomentellum. The fruits are green when younger and turning yellow when older $[8,9]$. A digital image of the aerial part of the plant is shown in Figure 1.

2.2. Propagation. G. mollis grows in the wild and can be propagated by seed or seedlings. The seeds are collected from the dried fruits that may have fallen on the ground [9].

\section{Uses of the Aerial Parts of G. mollis}

The different parts of G. mollis have been used for different purposes across the regions and places where the plant grows or is cultivated.

3.1. Mucilage from Leaves and Stem Bark. In the Democratic Republic of Congo, the bark is kneaded with water into a viscous substance that is added to sauces while, in Gabon, the inner bark is sometimes eaten as food. In Nigeria, the inner stem bark is used as thickener in soups and in local cakes made from beans or corn flour commonly called "Kosai" and "Punkasau" in Hausa (Nigeria), respectively [11, 12].

The infusion of the bark obtained by cold or hot maceration in water is applied to give a smooth surface to mud walls and floors [13] while the wood ash is used as salt substitute including the ash of the leaves, stems, and roots [9].
3.2. Vegetables and Fruits. The flowers, buds, and young shoots are added to soups and sauces as garnishing while, in Sudan, the young leaves are cooked and eaten as vegetables. The fruit is eaten raw or boiled [9].

3.3. Ethnomedicinal Uses. Several ethnomedicinal uses of the infusion, decoction, maceration, or mucilage from the leaves, roots, or stem bark of $G$. mollis have been documented. These ethnomedicinal uses are described in Table 1.

\section{Biological Evaluation and Chemical Constituents of $\mathbf{G}$. mollis}

Several scientists have investigated the histopathological and toxicological effects of extracts of $G$. mollis on laboratory animals.

Onwuliri et al. [14] conducted toxicological and histopathological studies in rats using the ethanolic extract of the stem bark of G. mollis. Tannins, saponins, flavonoids, glycosides, balsam, phenols, terpenes, and steroids were isolated from the stem bark, but alkaloids were absent. The extract exhibited toxic properties at the lethal dose $\left(\mathrm{LD}_{50}\right)$ of $1500 \mathrm{mg} / \mathrm{kg}$ body weight. The convoluted tubules of the kidney but no structural effects on the liver and heart were observed suggesting that the extract may be safe in humans but should be used with caution on patients with renal failure.

Studies by Obidah et al. [12] on the toxic effects of the stem bark of $G$. mollis showed that the addition of the pulverized stem bark to the normal diet of male Wister rats at concentrations of $0,1,5$, and $10 \%$ given to them as feed for 4 weeks, resulted in no deaths, and remarkable changes in appearance were not observed in the treated animals. However, rats fed with $10 \%$ dietary level showed significant $(P<0.05)$ increases in serum transaminases activities which was accompanied by decreased food intake. There was no observed effect on serum alkaline phosphatase activity, urea, creatinine, triglycerides, cholesterol, glucose concentrations, and body and organ weights in their study. These workers concluded that dietary exposure of rats to G. mollis stem bark powder at high concentrations (10\%) may cause some adverse effects, especially liver injury. 
<smiles>O=c1cc(-c2ccc(O)c(O)c2)oc2cc(O)cc(O)c12</smiles>

(a)<smiles>O=C1CC(c2ccc(OC3OC(CO)C(O)C(O)C3O)c(O)c2)Oc2cc(OC3OC(C(=O)O)C(O)C(O)C3O)cc(O)c21</smiles>

(b)

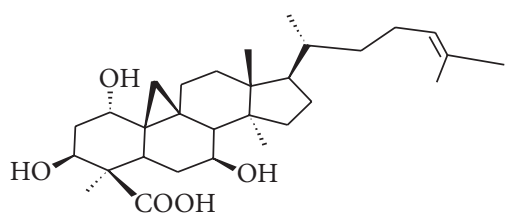

(c)

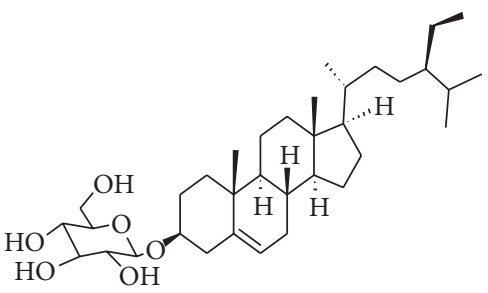

(f)

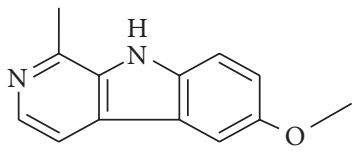

(g)

Figure 2: Molecular structure of isolates from aerial parts of G. mollis. (a) Luteolin, (b) 7-(1-O- $\beta$-D-galacturonide) $4^{\prime}$-(1-O- $\beta$-glucopyranosyl)$3^{\prime} 4^{\prime}, 5,7$-tetrahydroxyflavone, (c) 7 $\beta$-hydroxy-23-enedeoxojessic acid, (d) $7 \beta$-hydroxy-23-deoxojessic acid, (e) $\beta$-sitosterol, (f) $\beta$-sitosterol-3O-glucoside, and (g) 6-Methoxyharmane.

It may be argued however that gum extracted from the stem bark of $G$. mollis when used as excipient is incorporated into formulations in smaller proportions usually lower than the $10 \%$ proportion added to the feed of the animals in the foregoing study. Consequently, it may be expected that the low use level of $G$. mollis gum as excipient in formulations should not cause any adverse effects in humans.

Asuku et al. [15] evaluated the methanolic extract of $G$. mollis leaves for its antioxidant and hepatoprotective properties by an in vivo procedure. They reported significant $(P<0.05)$ hepatoprotective potential evidenced by the lowering of serum levels of bilirubin, aspartate aminotransferase, and alanine aminotransferase and decreasing of malondialdehyde levels in rats pretreated or posttreated with carbon tetrachloride $\left(\mathrm{CCl}_{4}\right)$. They concluded that $G$. mollis leaves contain potent antioxidant compounds that could offer protection against hepatotoxicity and ameliorate preexisting liver damage and oxidative stress conditions.

Saleem et al. [16] assessed the nutritive value of the leaves and fruits of three grewia species under semiarid environment, and the results of the study indicated that the three species could be introduced as a source of fodder in animal production farms and silvopastoral systems.

4.1. Compounds Isolated from G. mollis. Al-Youssef et al., [17] evaluated the methanolic extract of the aerial part of $G$. mollis and reported isolation of a number of phytochemical constituents such as flavonoids (luteolin and 7-(1-O- $\beta$-Dgalacturonide)- $4^{\prime}$-(1-O- $\beta$-glucopyranosyl)-3' $4^{\prime}, 5,7$-tetrahydroxyflavone), triterpenoids (7 $\beta$-hydroxy-23-enedeoxojessic acid and 7 $\beta$-hydroxy-23-deoxojessic acid), and steroids
( $\beta$-sitosterol and $\beta$-sitosterol-3-O-glucoside). The molecular structures of these isolates are shown in Figure 2.

Rosler et al. [18] earlier reported the isolation of 6-methoxyharmane (Figure 2(g)), a Harman alkaloid from G. mollis. Harman alkaloids belong to the class of $\beta$-carbolines. They bind strongly to benzodiazepine receptors in the brain to induce inverse agonist effects to benzodiazepines such as convulsive, anxiogenic, and memory enhancing effects [1921].

Efiom and Oku [22], working on the n-hexane fraction of G. mollis root extract collected in Niger State, Nigeria, isolated two triterpene compounds, lup-20-en-3-ol and 1,3hexyloxacyclotridec-10-en-2-one.

4.2. Phytochemical Screening, Antibacterial and Anti-Inflammatory Properties. Shagal et al. [23] reported the presence of saponins and phenolic compounds in the ethanol fraction of $G$. mollis leaves while glycosides were additionally present in the ethanolic stem bark extracts. Tannins, volatile oils, and flavonoids were also observed in the ethanolic root extracts.

Antibacterial studies on the ethanolic leaf and root extracts were reported to exhibit inhibitory activity against Staphylococcus aureus and Escherichia coli while the stem bark extract exhibited activity against $S$. aureus and Salmonella typhi. The aqueous root extracts showed no inhibition against the same organisms except for the aqueous leaf extract which showed some inhibitory activity against Streptococcus spp. and E. coli. The aqueous extract of the stem bark also exhibited inhibition against $S$. typhi which possibly justifies the use of the plant in the treatment against diarrhoea and dysentery. 
Al-Youssef et al. [17] investigated the in vitro antibacterial activity of the aerial part of G. mollis collected in Akba-AlAbar, Saudi Arabia, against various strains of bacteria such as Staphylococcus epidermidis (ATCC 9615), Bacillus subtilis (ATCC 1174), S. aureus (ATCC 25175), Klebsiella pneumonia (ATCC 33495), Pseudomonas aeruginosa (ATCC 12453), and E. coli (ATCC 10536). Moderate inhibitory activity was exhibited by the methanolic extract against S. epidermidis, $B$. subtilis, and $S$. aureus when compared with the standard antibiotics cloxacillin ( $5 \mathrm{mcg} / \mathrm{disc})$, amoxicillin ( $10 \mathrm{mcg} / \mathrm{disc})$, and ciprofloxacin ( $5 \mathrm{mcg} / \mathrm{disc})$. The extract also showed inhibitory activity against oral cavity pathogen, $S$. aureus, at MIC value of $64 \mathrm{mcg} / \mathrm{ml}$ and $128 \mathrm{mcg} / \mathrm{ml}$ against methicillin resistant S. aureus (MRSA, ATCC 15187), respectively. The authors reported a time and concentration dependent killing by the methanolic extract of $G$. mollis against $S$. aureus (ATCC 25175).

The development of a new class of polyurethane nanofibers containing aqueous extract of aerial parts of $G$. mollis by one step electrospinning was reported by Musarat et al. [25] for its potential biomedical application as an antimicrobial fiber. They incorporated the aqueous extract into the polymer media in order to influence the morphology and size of the polyurethane nanofibers. Further testing of the extract loaded nanofibers was also observed to inhibit the growth of $E$. coli (ATCC 52922) and S. aureus (ATCC 29231).

Al-Youssef et al. [17] also investigated the anti-inflammatory activity of the same extract at $500 \mathrm{mg} / \mathrm{kg}$ which showed pronounced anti-inflammatory effect after two hours. Their findings provide preliminary evidence suggesting that fractions of G. mollis exhibit inhibitory effects in inflammatory process and support the use of this plant for the treatment of arthritis, dermatitis, and wounds in African and Saudi Arabian traditional medicine.

\section{Grewia Polysaccharide Gum}

Interest in grewia polysaccharide gum as a pharmaceutical excipient has been on for over a decade [26]. This growing interest is informed by the viscous property of the gum extracted from the inner stem bark of the G. mollis plant. Consequently, the gum has been extracted and some of its physicochemical properties evaluated.

5.1. Extraction and Purification. Several approaches to the extraction of the gum from the inner stem bark of the shrub have been reported [27-30]. Briefly, the dried and pulverized inner stem bark of the G. mollis shrub is dispersed in demineralized water using an impeller. The fibrous material from the dispersed mucilage is removed by straining through a muslin cloth. Thereafter the mucilage is centrifuged before extraction of the gum with $96 \%$ ethanol. The extracted gum is redispersed in water and reextracted to get a beige-coloured gum which is then dried in an oven at $50^{\circ} \mathrm{C}$ for $8 \mathrm{~h}$.

The gum can be further purified by treatment with $0.1 \mathrm{M}$ sodium hydroxide or hydrochloric acid or with sodium chloride followed by extraction with $96 \%$ ethanol. It must be noted that treatment of the natural material with dilute alkali, dilute acid, or electrolytes could result in modification of the parent material with consequent variations in the physicochemical properties of the resultant material.

5.2. Some Physicochemical Properties of Grewia Gum. The gum contains traces of metals ( $\mathrm{Ca}, \mathrm{K}, \mathrm{Na}, \mathrm{Mg}, \mathrm{Zn}$, and $\mathrm{Fe}$ ) and a viscosity-average-molecular weight of 316,000 [28]. Metals constitute about $6.1 \%$ of the gum, while proteins and lipids account for 1.24 and $0.021 \%$, respectively. It has a high intrinsic viscosity with a swelling capacity greater than tragacanth and methylcellulose.

Grewia polysaccharide gum slowly hydrates and swells in water. The gum has aqueous solubility of about $0.2 \mathrm{mg} / \mathrm{mL}$ [29]. The low solubility of the gum was attributed to insoluble cell-wall materials making up a larger proportion of the gum. However, the presence of acetyl groups has been reported to account for the insolubility of certain gums in water [31]. Grewia polysaccharide gum has been shown from Fouriertransformed infrared (FTIR) spectroscopic studies to contain acetyl groups which may account for the low solubility of the gum in water [29]. Generally, water poorly soluble gums due to presence of acetyl groups are improved by deacetylation with dilute ammonia [31-33].

The rheological properties of the gum dispersion and the water vapour permeability of aqueous-based grewia gum films have been reported [27, 34]. The aqueous dispersions of the gum at different concentrations exhibited pseudoplastic flow behaviour. The viscosities of the gum dispersions decrease with increase in temperature. The effect of incorporation of electrolytes to dispersions of the gum was also investigated. The result showed a decrease in the viscosity of the gum brought about by electrolyte which is proportional to the concentration as well as the valence of the cation, and these findings have been confirmed by other workers [29].

5.3. Chemistry of Grewia Gum. Okafor [27] using paper chromatography reported that the primary structure of grewia polysaccharide gum may comprise of d-glucose, d-rhamnose and galacturonic acid. Nep and Conway [29, 35] determined the monosaccharide composition of the gum using gas chromatography. These workers reported that the primary structure of grewia gum may comprise five neutral sugars: $d$ rhamnose, d-arabinose, d-xylose, d-galactose, and d-glucose (Figure 3). The mean relative concentrations of these sugars in the polysaccharide were determined as glucose $(67.14 \%)$, rhamnose $(6.2 \%)$, xylose $(2.72 \%)$, galactose $(9.61 \%)$, and arabinose (12.71\%).

The FTIR spectral analysis of the gum exhibited the typical bands and peak characteristics of polysaccharides [29] as shown in Figure 4. These authors attributed the broad band occurring at about $3425 \mathrm{~cm}^{-1}$ to the presence of hydroxyl $(-\mathrm{OH})$ groups while the peak obtained at about $2927 \mathrm{~cm}^{-1}$ was attributed to stretching modes of the $\mathrm{C}-\mathrm{H}$ bonds of methyl groups $\left(-\mathrm{CH}_{3}\right)$ of the rhamnose. Absorption bands around 1618 and $1420 \mathrm{~cm}^{-1}$ were attributed to carboxylate groups of uronic residues of galacturonic acid while the region between 1500 and $1800 \mathrm{~cm}^{-1}$ and absorption peaks at $1735 \mathrm{~cm}^{-1}$ and $1256 \mathrm{~cm}^{-1}$ were linked to the presence of carboxylic and acetyl groups, respectively. The absorption 


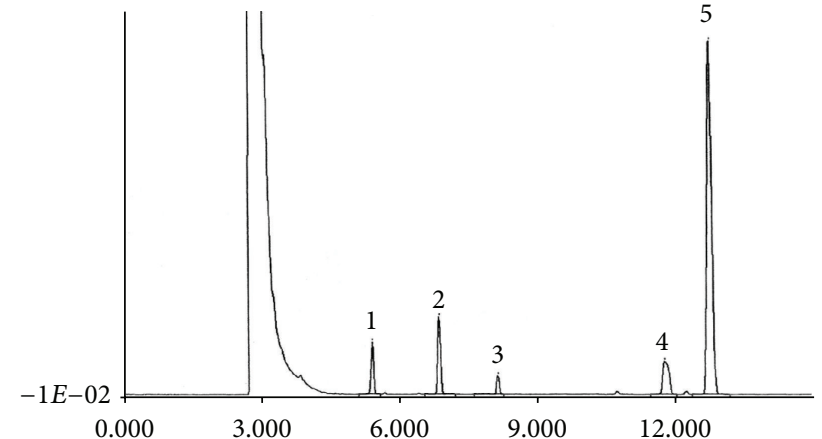

FIGURE 3: GC chromatograms of alditol acetates from grewia polysaccharide gum after hydrolysis with $2 \mathrm{~N} \mathrm{H}_{2} \mathrm{SO}_{4}$ (Adapted from Nep and Conway [29]).

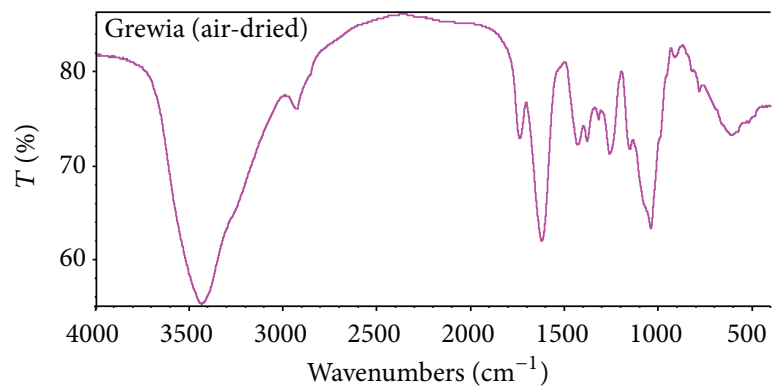

Figure 4: FT-IR spectra of grewia gum (adapted from Nep and Conway [29]).

band between 500 and $900 \mathrm{~cm}^{-1}$ may represent the finger print region for grewia polysaccharide gum.

The gum has also been characterized using other techniques such as scanning electron microscopy (SEM), gel permeation chromatography (GPC), differential scanning calorimetry (DSC), and thermogravimetric analysis of the extracted sample. Also, spectroscopic techniques such as Xray photoelectron spectroscopy (XPS), solid-state nuclear magnetic resonance (NMR), and $1 \mathrm{H}$ and $13 \mathrm{C}$ NMR techniques [29] have been employed in the characterization of grewia gum. Based on findings from the various techniques, the gum has been described as a typically amorphous polysaccharide gum of high thermal stability with an average molecular weight of $5925 \mathrm{kDa}$ expressed as the pullulan equivalent.

The effect of drying methods (air-drying, freeze-drying, and spray-drying) on the physicochemical properties of the gum has been investigated using the techniques outlined above [35]. Solid-state NMR results indicated that drying technique had little effect on the structure of the polysaccharide gum, but X-ray photoelectron spectroscopy (XPS) showed that surface chemistry of the gum varied with drying methods. Thermogravimetric analyses showed that oxidation onset varied according to the drying method. The workers concluded that, for industrial extrapolation, air-drying of the gum may be preferable to spray-drying and freeze-drying when relative cost, product stability, and powder flow are the priority, in tablet formulation, for instance.

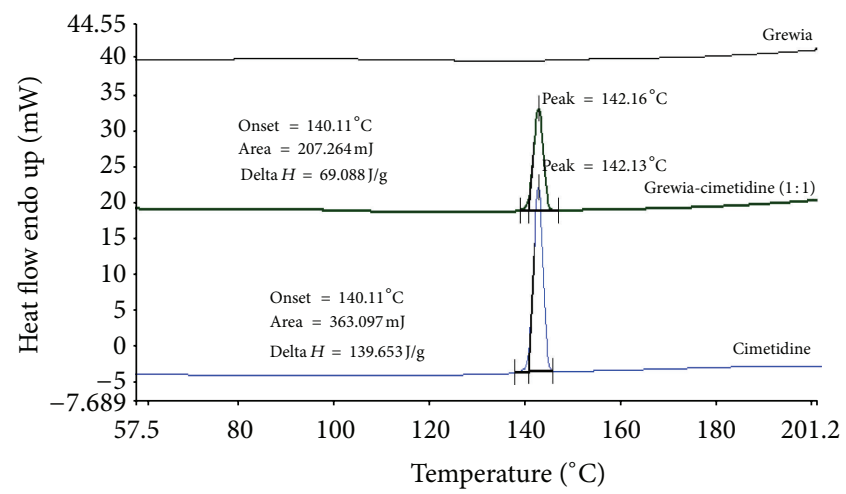

FIGURE 5: DSC traces for cimetidine, grewia gum, and cimetidine/ grewia gum physical mixture $(1: 1)$ under nitrogen atmosphere and a scan rate of $10^{\circ} \mathrm{C} / \mathrm{min}$ up to $200^{\circ} \mathrm{C}$ (adapted from Nep and Conway [39]).

\section{Pharmaceutical Values of Grewia Polysaccharide Gum}

6.1. Preformulation Studies. The assessment of possible interactions between a drug and different excipients used in formulation usually precedes large scale development trials of solid dosage forms $[36,37]$. Physical and chemical interactions between excipients and active pharmaceutical ingredients (API) are common place [38] and necessitate the screening of novel excipients for possible incompatibilities. In view of the suitability of grewia polysaccharide gum as formulation excipient in solid or liquid dosage forms, studies on the potential interaction or incompatibility of the gum with pharmaceutical actives and/or excipients used in solid dosage formulation are imperative.

Nep and Conway [39] investigated potential interactions between grewia gum and cimetidine, ibuprofen, and some standard excipients used in the formulation of tablets (Figure 5). The thermal and molecular behaviours of mixtures of grewia gum with cimetidine, ibuprofen, and the standard excipients (lactose monohydrate, magnesium stearate, colloidal silicone dioxide, and microcrystalline cellulose) were analyzed using differential scanning calorimetry and FT-IR spectroscopy to assess potential interactions. The results obtained indicated that grewia gum is an inert natural polymer which can be used alone or in combination with other excipients in the formulation of pharmaceutical dosage forms.

6.2. Pharmaceutical Applications. Investigations into the pharmaceutical application of gum from G. mollis were first reported in the early 2000s [27, 28, 34, 40, 41]. The gum was reported to possess excellent binding property in sodium salicylate tablets (Okafor and Chukwu [40]). It was found to be as effective as gelatin when employed as a binder in concentrations of $2-6 \% \mathrm{w} / \mathrm{w}$. At the same concentration, the gum was more effective as a binder than maize starch or acacia gum.

Audu-Peter and Gokum [42] found that the method of incorporating the gum into tablet formulation had effect 


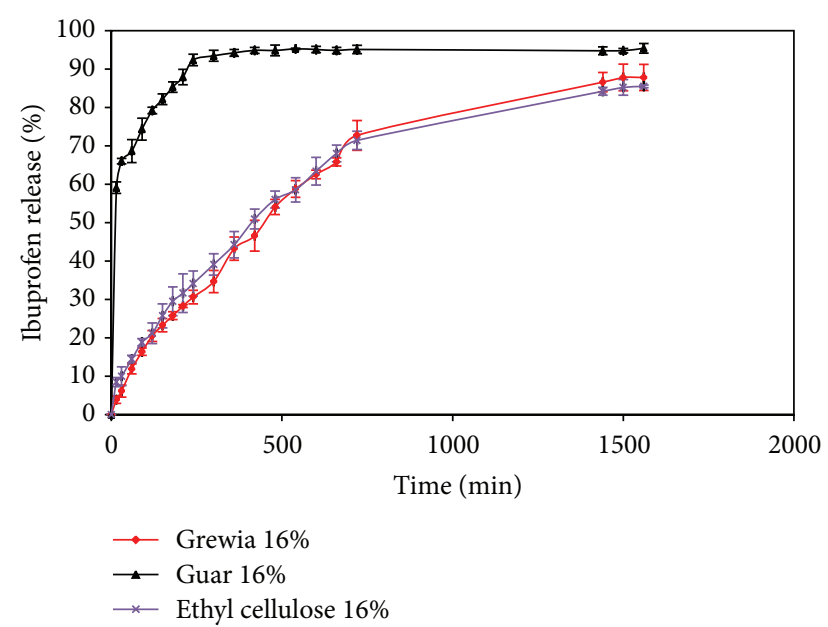

FIGURE 6: Release profiles of ibuprofen from the matrices containing $16 \% \mathrm{w} / \mathrm{w}$ of grewia, guar, or ethyl cellulose in phosphate buffer solution at $37 \pm 1^{\circ} \mathrm{C}(n=3$, mean $\pm \mathrm{sd})$ (adapted from Nep and Conway [44]).

on tablet properties. They discovered that tablets with better tablet properties such as hardness and friability were produced when the gum was incorporated by activation with water than by wet granulation or direct compression. Acid and thermal treatment of the gum resulted in improved drug release from tablets attributable to reduced viscosity of the gum (Audu-Peter and Isah [43]).

Emeje et al. [28] in 2008 investigated the binding property of the gum. These workers compared the binding property of the gum with polyvinyl pyrolidone in paracetamol tablet formulations and analysed the compression properties of the formulations using density measurements and application of Heckel and Kawakita equation. They found that grewia gum compares favourably with the standard binder PVP and may be a useful substitute binder in paracetamol formulations.

Grewia gum has been investigated as a sustained release polymer matrix in ibuprofen [44]. It was used at a concentration of $16 \%, 32 \%$, or $48 \%$ to formulate tablets of ibuprofen. This was compared with similar formulations prepared using hydroxypropyl methylcellulose (HPMC), guar gum, or ethyl cellulose as the polymer matrix. The results indicated that grewia gum at these concentrations was capable of sustaining the release of ibuprofen tablets up to 24 hours (Figure 6). Similarly, these scientists demonstrated the potential of grewia gum to sustain the release of a water-soluble drug in tablet formulations [45]. Tablets of cimetidine containing $40 \%$ of grewia gum were prepared by direct compression.

Similar formulations containing HPMC, gum Arabic, carboxy methylcellulose, or ethyl cellulose were prepared for comparison. The results indicated that grewia gum was superior to hydrophilic matrices of HPMC, carboxy methylcellulose, and gum Arabic in sustaining the release of cimetidine from tablets. In both instances, the workers concluded that grewia gum may be a useful excipient when used alone or in combination with other polymers to modify the release of soluble drugs or poorly soluble drugs from polymeric matrices.
Grewia gum fractions obtained by centrifugation at $4500 \mathrm{rpm}$ for 30 minutes with average molecular weights between 230 and $235 \mathrm{kDa}$ have been shown to demonstrate improved aqueous solubility that was useful in delivering more solids to the substrate when used as a film coating agent $[26,30]$.

Grewia gum has also been evaluated as a mucoadhesive in tablets [46-48]. Nep and Okafor [47] showed that the gum compared favourably with tragacanth when used as bioadhesive in tablet formulation. Nep and Conway [48] compared the mucoadhesive performance of compacts or gels of grewia polysaccharide gum with those of guar gum, carboxymethylcellulose, hydroxypropyl methylcellulose, and carbopol 971P. A software-controlled penetrometre, TA.XTPlus texture analyzer (Stable Microsystems, UK) was used to measure the detachment force of the compacts while the polymer gels were evaluated for hardness, stickiness, work of cohesion, and work of adhesion. The results showed that grewia gels had a significantly greater work of adhesion than carboxymethylcellulose gels $(P<$ $0.05)$ and HPMC gels $(P<0.001)$. The mucoadhesive performance of grewia compacts was comparable to those of HPMC and carbopol 971P compacts $(P>0.05)$. It was concluded that grewia polysaccharide gum should be suitable for the formulation of retentive drug delivery devices.

The application of the gum as a suspending agent in paediatric formulations has been reported [49-51]. The suspending ability of air-dried or freeze-dried grewia gum in ibuprofen suspension was compared with similar suspension formulations containing xanthan gum, sodium carboxymethylcellulose, or acacia gum as suspending agents [49]. The stability of the ibuprofen suspension formulations was assessed using parameters such as appearance, pourability, viscosity, rheology, sedimentation volume and redispersibility. Other evaluation parameters used include degree of flocculation, zeta potential, and microbial load. The result from the study indicated that air-dried or freeze-dried grewia gum may provide a suitable alternative as suspending agent in paediatric suspension formulations.

\section{Conclusion}

Grewia gum is a natural resource whose potential pharmaceutical values have been established. Our literature survey revealed that, pharmaceutically, grewia gum has been well investigated for its application as binder, disintegrant or mucoadhesive in solid dosage forms and as stabilizer or suspending agent in liquid formulations. However, the scientific research on grewia gum is yet to be translated into industrial applications due to the absence of detailed physical and chemical characterization, stability data, and scientifically validated bioactive properties. Although the use of grewia gum as thickener in local delicacies spans generations, it may be necessary to reconcile the ethnomedicinal use of extract of the aerial parts of the plant with the absolute requirement that excipients are pharmacologically inert. Detailed scientific investigations that will fill in these details will not only help in furthering the scientific understanding of grewia gum, but importantly it will assist in realizing its commercial 
potential as pharmaceutical excipient. Furthermore, grewia gum should be explored in design and development of other drug carriers such as micro- and nanomaterials, membranes, capsules, and hot-melt extruded carriers and in wound healing applications. Grewia gum holds promise as an excipient to be explored for the unmet needs in drug delivery.

\section{Conflict of Interests}

The authors certify that there is no conflict of interests with any financial organization regarding the material discussed in the paper.

\section{References}

[1] C. W. Vendruscolo, C. Ferrero, E. A. G. Pineda et al., "Physicochemical and mechanical characterization of galactomannan from Mimosa scabrella: effect of drying method," Carbohydrate Polymers, vol. 76, no. 1, pp. 86-93, 2009.

[2] H. E. Huber and G. I. Christenson, "Utilization of hydrophilic gums for control of drug release from tablet formulation. 1: disintegration and dissolution behaviour," Journal of Pharmaceutical Sciences, vol. 1, pp. 59-66, 1996.

[3] T. R. Bhardwaj, M. Kanwar, R. Lal, and A. Gupta, "Natural gums and modified natural gums as sustained-release carriers," Drug Development and Industrial Pharmacy, vol. 26, no. 10, pp. 10251038, 2000.

[4] J. Varshosaz, N. Tavakoli, and S. A. Eram, "Use of natural gums and cellulose derivatives in production of sustained release metoprolol tablets," Drug Delivery: , vol. 13, no. 2, pp. 113-119, 2006.

[5] O. K. Udeala and A. Chukwu, "The binding property of mucuna gum in sulphadimidine and chloroquine phosphate tablets," Nigerian Journal of Pharmaceutical Sciences, vol. 1, pp. 59-66, 1985.

[6] M. R. Bilany, "Suspensions and emulsions," in Pharmaceutics: The Design and Manufacture of Medicines, M. E. Aulton, Ed., pp. 383-405, Churchill Livingstone, Philadelphia, Pa, USA, 3rd edition, 2007.

[7] D. L. Middleton, S. H. S. Leung, and J. R. Robinson, "Ocular bioadhesive delivery systems," in Bioadhesive Drug Delivery Systems, V. Leenaerts and R. Gurny, Eds., pp. 179-202, CRC Press, Boca Raton, Fla, USA, 1990.

[8] C. Whitehouse, M. Cheek, S. Andrews, and B. Verdcourt, "Tiliaceae and Muntingiaceae," in Flora of Tropical East Africa, H. J. Beentje, Ed., p. 120, A.A. Balkema, Rotterdam, Netherlands, 2001.

[9] D. Louppe, A. A. Oteng-Amoako, and M. Brink, Plant Resources of Tropical Africa 7(1). Timber 1, PROVA Foundation, Wageningen, Netherlands; Backhuys Publishers, Lenden, Netherlands; CTA, Wageningen, Netherlands, pp. 298-300, 2008.

[10] "Digital image of Grewia mollis plant," http://www.prota4u .org/protav8.asp?h=M11,M15,M17,M18,M25,M26,M27,M34, M36,M4,M6,M7,M8,M9\&t=Grewia,mollis\&p=Grewia + mollis \#Description.

[11] L. S. Gill, Ethno-Medical Uses of Plants in Nigeria, University of Benin Press, Benin, Nigeria, 1992.

[12] W. Obidah, J. L. Godwin, J. Z. Fate, and M. A. Madusolumuo, "Toxic effects of Grewia mollis stem bark in experimental rats," Journal of American Science, vol. 6, no. 12, pp. 1544-1548, 2010.
[13] J. M. Dalziel, The Useful Plants of West Africa, Crown Agents, London, UK, 1937.

[14] F. C. Onwuliri, J. D. Mawak, D. L. Wonang, and E. A. Onwuliri, "Phytochemical toxicological and histo-pathological studies of some medicinal plants in Nigeria," International Journal of Natural and Applied Sciences, vol. 2, pp. 225-229, 2006.

[15] O. Asuku, S. E. Atawodi, and E. Onyike, "Antioxidant, hepatoprotective, and ameliorative effects of methanolic extract of leaves of Grewia mollis Juss. on carbon tetrachloride-treated albino rats," Journal of Medicinal Food, vol. 15, no. 1, pp. 83-88, 2012.

[16] N. A. Saleem, M. El-Nour, and A. A. M. Khalid, "The nutritive value of leaves and fruits of three grewia species under semi-arid environment," Journal of Agricultural Science and Technology, vol. B2, pp. 956-964, 2012.

[17] H. M. A. Al-Youssef, M. Amina, and A. M. El-Shafae, "Biological evaluation of constituents from Grewia mollis," Journal of Chemical and Pharmaceutical Research, vol. 4, no. 1, p. 508, 2012.

[18] H. Rosler, H. Framm, and R. N. Blomster, "The isolation of 6-hydroxyharmane from Grewia mollis," Journal of Natural Products, vol. 41, no. 4, pp. 383-384, 1978.

[19] W. Pfau and K. Skog, "Exposure to $\beta$-carbolines norharman and harman," Journal of Chromatography B, vol. 802, no. 1, pp. 115126, 2004.

[20] P. K. Goyal, "Phytochemical and pharmacological properties of the genus Grewia: a review," International Journal of Pharmacy and Pharmaceutical Sciences, vol. 4, no. 4, pp. 72-78, 2012.

[21] P. Venault and G. Chapouthier, "From the behavioral pharmacology of beta-carbolines to seizures, anxiety, and memory," The Scientific World Journal, vol. 7, pp. 204-223, 2007.

[22] O. O. Efiom and E. Oku, "Isolation and characterisation of triterpene lup-20-en-3-ol and 1, 3-hexyloxacyclotridec-10-en-2one from the root of Grewia mollis," New York Science Journal, vol. 5, no. 11, pp. 138-141, 2012.

[23] M. H. Shagal, D. kubmarawa, and Z. Idi, "Phytochemical screening and antimicrobial activity of roots, stembark and leaf extracts of Grewia mollis," African Journal of Biotechnology, vol. 11, no. 51, pp. 11350-11353, 2012.

[24] N. Idika and M. Niemogha, "The diversity of uses of medicinal plants in Nigeria," in A Textbook of Medicinal Plants of Nigeria, T. Odugbemi, Ed., p. 63, University of Lagos Press, Lagos, Nigeria, 2008.

[25] A. Musarat, H. M. Al-Youssef, T. Amna et al., "Polyurethane/ G.mollis composite nanofibers for biomedical applications," Journal of Nanoengineering and Nanomanufacturing, vol. 2, pp. 85-90, 2012.

[26] I. J. Ogaji, E. I. Nep, and J. D. Audu-Peter, "Advances in natural polymers as pharmaceutical excipients," Pharmaceutica Analytica Acta, vol. 3, article 146, 2012.

[27] I. S. Okafor, “The rheological properties of grewia gum," Nigeria Journal of Polymer Science and Technology, vol. 2, pp. 169-175, 2001.

[28] M. Emeje, C. Isimi, and O. Kunle, "Effect of Grewia gum on the mechanical properties of Paracetamol tablet formulations," African Journal of Pharmacy and Pharmacology, vol. 2, pp. 1-6, 2008.

[29] E. I. Nep and B. R. Conway, "Characterization of Grewia Gum, a potential pharmaceutical excipient," Journal of Excipients and Food Chemicals, vol. 1, no. 1, pp. 30-40, 2010.

[30] I. Ogaji, "Characterization and application of grewia gum as a film coating agent in theophylline hydrochloride tablets," Pharmaceutics and Pharmaceutical Technology, vol. 308, 2011. 
[31] A. Setia, S. Goyal, and N. Goyal, "Applications of gum karaya in drug delivery systems: a review on recent research," Der Pharmacia Lettre, vol. 2, no. 5, pp. 39-48, 2010.

[32] D. Le Cerf, F. Irinei, and G. Muller, "Solution properties of gum exudates from Sterculia urens (Karaya gum)," Carbohydrate Polymers, vol. 13, no. 4, pp. 375-386, 1990.

[33] A. Imeson, "Exudate gums," in Thickening and Gelling Agents For Food, A. Imeson, Ed., pp. 66-97, Chapman and Hall, London, UK, 1992.

[34] I. S. Okafor and A. Chukwu, "Water vapour permeability of aqueous-based grewia gum film," Nigeria Journal of Polymer Science and Technology, vol. 2, pp. 176-182, 2003.

[35] E. I. Nep and B. R. Conway, "Physicochemical characterization of grewia polysaccharide gum: effect of drying method," Carbohydrate Polymers, vol. 84, no. 1, pp. 446-453, 2011.

[36] G. Bruni, V. Berbenni, C. Milanese, A. Girella, and A. Marini, "Drug-excipient compatibility studies in binary and ternary mixtures by physico-chemical techniques," Journal of Thermal Analysis and Calorimetry, vol. 102, no. 1, pp. 193-201, 2010.

[37] M. J. Peres-Filho, M. P. N. Gaeti, S. R. De Oliveira, R. N. Marreto, and E. M. Lima, "Thermoanalytical investigation of olanzapine compatibility with excipients used in solid oral dosage forms," Journal of Thermal Analysis and Calorimetry, vol. 104, no. 1, pp. 255-260, 2011.

[38] M. E. Brown, E. M. Antunes, B. D. Glass, M. Lebete, and R. B. Walker, "DSC screening of potential prochlorperazineexcipient interactions in preformulation studies," Journal of Thermal Analysis and Calorimetry, vol. 56, no. 3, pp. 1317-1322, 1999.

[39] E. I. Nep and B. R. Conway, "Preformulation studies on grewia gum as a formulation excipient," Journal of Thermal Analysis and Calorimetry, vol. 108, no. 1, pp. 197-205, 2012.

[40] I. S. Okafor and A. Chukwu, "The binding property of Grewia gum in sodium salicylate tablets," West African Journal of Biological Sciences, vol. 14, pp. 9-21, 2003.

[41] I. S. Okafor and I. M. Danat, "The influence of granulating solvents on drug release from tablets containing grewia gum," Journal of Pharmacy and Bioresources, vol. 1, pp. 76-83, 2004.

[42] J. D. Audu-Peter and B. G. Gokum, "Effect of methods of incorporating grewia gum as binder on tablet properties," Nigerian Journal of Pharmaceutical Research, vol. 4, pp. 68-73, 2005.

[43] J. D. Audu-Peter and S. Isah, "Evaluation of grewia gum as binder in paracetamol tablet," Journal of Pharmacy and Bioresources, vol. 4, pp. 68-73, 2007.

[44] E. I. Nep and B. R. Conway, "Grewia polysaccharide as a pharmaceutical excipient in matrix tablets," Journal of Excipients and Food Chemicals, vol. 2, no. 1, pp. 3-15, 2011.

[45] E. I. Nep and B. R. Conway, "Polysaccharide gum matrix tablets for oral controlled delivery of cimetidine," Journal of Pharmaceutical Sciences and Research, vol. 2, no. 11, pp. 708-716, 2010.

[46] E. I. Nep and I. S. Okafor, "Evaluation of the bioadhesive property of Grewia Gum in mebendazole tablet formulation 1: in pig gastric mucus," Nigerian Journal of Pharmaceutical Research, vol. 4, no. 2, pp. 52-58, 2005.

[47] E. I. Nep and I. S. Okafor, "Evaluation of the bioadhesive property of Grewia gum in indomethacin tablet formulation in pig gastric mucus," Journal of Pharmacy and Bioresources, vol. 3, no. 2, pp. 62-69, 2006.

[48] E. I. Nep and B. R. Conway, "Grewia gum 2: mucoadhesive properties of compacts and gels," Tropical Journal of Pharmaceutical Research, vol. 10, no. 4, pp. 393-401, 2011.
[49] E. I. Nep and B. R. Conway, "Evaluation of Grewia polysaccharide gum as a suspending agent," International Journal of Pharmacy and Pharmaceutical Sciences, vol. 3, no. 2, pp. 168173, 2011.

[50] J. O. Kadiri and I. S. Okafor, "Evaluation of the suspending property of Grewia gum in metronidazole suspension," Nigerian Journal of Pharmaceutical Research, vol. 8, no. 1, pp. 247-254, 2010.

[51] I. J. Ogaji and S. W. Hoag, "Effect of Grewia gum as a suspending agent on ibuprofen pediatric formulation," AAPS PharmsciTech, vol. 12, no. 2, pp. 507-513, 2011. 

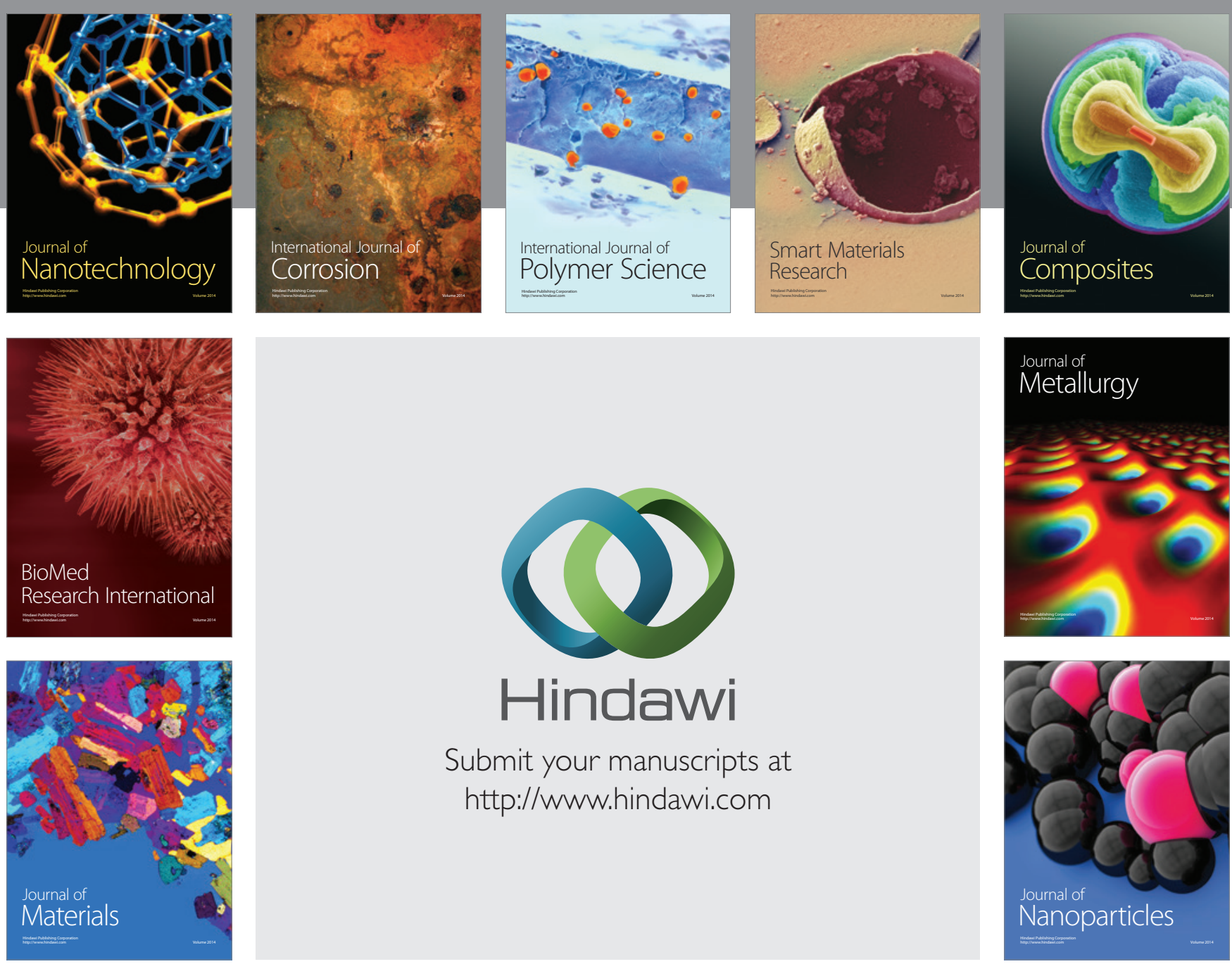

Submit your manuscripts at http://www.hindawi.com
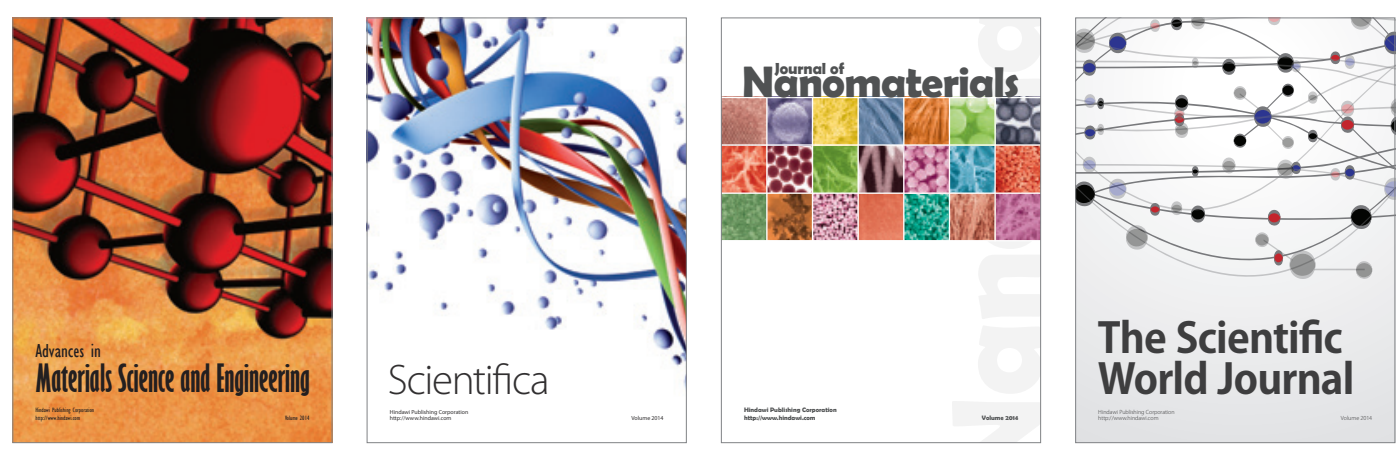

\section{The Scientific World Journal}
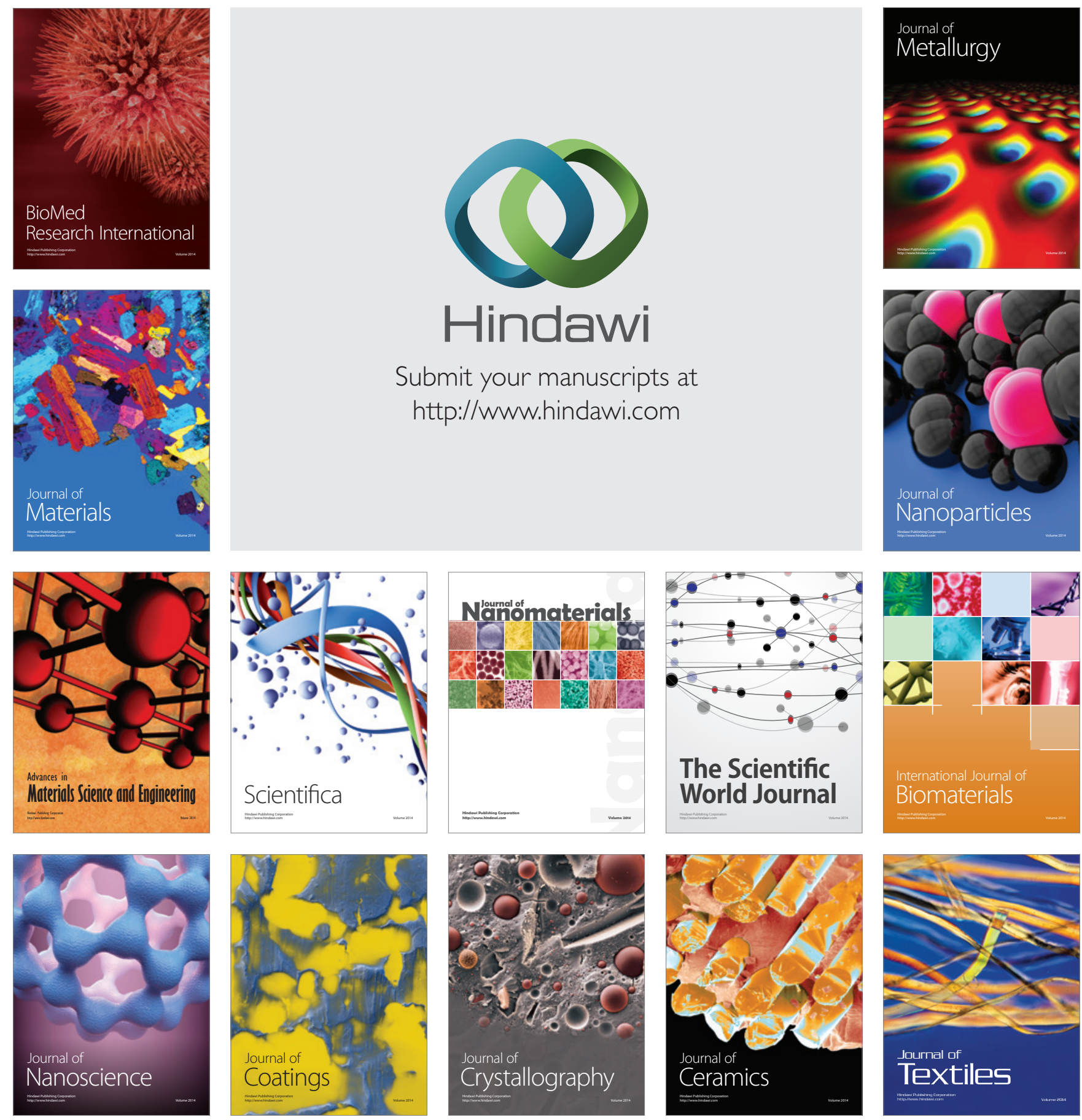